\title{
Chemo-radiation with or without mandatory split in anal carcinoma: experiences of two institutions and review of the literature
}

\author{
Christoph Oehler*+1, Sawyna Provencher², David Donath³, Jean-Paul Bahary³ ${ }^{3}$ Urs M Lütolf1 and I Frank Ciernik4,5
}

\begin{abstract}
Background: The split-course schedule of chemo-radiation for anal cancer is controversial.

Methods: Eighty-four patients with invasive anal cancer treated with definitive external beam radiotherapy (RT) with a mandatory split of 12 days (52 patients, Montreal, Canada) or without an intended split (32 patients, Zurich, Switzerland) were reviewed. Total RT doses were 52 Gy (Montreal) or 59.4 Gy (Zurich) given concurrently with 5-FU/ MMC.

Results: After a mean follow-up of $40 \pm 27$ months, overall survival and local tumor control at 5 years were $57 \%$ and $78 \%$ (Zurich) compared to $67 \%$ and $82 \%$ (Montreal), respectively. Split duration of patients with or without local relapse was $15 \pm 7 \mathrm{~d}$ vs. $14 \pm 7 \mathrm{~d}$ (Montreal, NS) and $11 \pm 11 \mathrm{~d}$ vs. $5 \pm 7 \mathrm{~d}$ (Zurich; $P<0.001$ ). Patients from Zurich with prolonged treatment interruption ( $\geq 7 \mathrm{~d}$ ) had impaired cancer-specific survival compared with patients with only minor interruption $(<7 \mathrm{~d})(P=0.06)$. Bowel toxicity was associated with prolonged $\mathrm{RT}(P=0.03)$ duration as well as increased relapse probability $(P=0.05)$. Skin toxicity correlated with institution and was found in $79 \%$ (Montreal) and 28\% (Zurich) $(P<0.0001)$.

Conclusions: The study design did not allow demonstrating a clear difference in efficacy between the treatment regimens with or without short mandatory split. Cause-specific outcome appears to be impaired by unplanned prolonged interruption.
\end{abstract}

\section{Introduction}

Sphincter-sparing radiotherapy (RT) alone or chemoradiation (CRT) with fluorouracil (5-FU) and mitomycin-C (MMC) is the standard of care for curative treatment of squamous cell carcinoma of the anal canal [1-5]. The Radiation Therapy Oncology Group (RTOG) experience with chemoradiation for advanced stage anal cancer has shown a local failure rate of $20 \%$ to $30 \%$ with radiotherapy doses of 45 to $50 \mathrm{~Gy}$ [2]. Increasing the radiotherapy dose to 59.4 Gy did not appear to increase local control when given in split-course fashion [6].

Concerns about an incorporation of a split in the chemoradiation for squamous cancer have been expressed for years because prolonged RT duration is a

* Correspondence: chris.oehler@bluewin.ch

1 Department of Radiation Oncology, Zurich University Hospital, Zurich,

Switzerland

† Contributed equally

Full list of author information is available at the end of the article known adverse prognostic factor [2,6,7]. In the last few years some institutions have started to omit the mandatory split completely for high-dose RT above $50 \mathrm{~Gy}$ in anal cancer [8-11]. Feasibility data have been inconsistent and the recent RTOG 92-08 trial which evaluated 59.4 Gy without mandatory split demonstrated comparable or favourable survival and tumor control compared with split-regimen $[8,10,11]$. Currently there is no standard in terms of mandatory split and it is unclear whether continuous CRT should be recommended as standard of care for the treatment of anal cancer.

The aim of this analysis was to retrospectively compare the outcome after modern high-dose EBRT with concurrent chemotherapy with or without mandatory split as treated at two independent institutions. We further investigated the feasibility of 3D-CRT (59.4 Gy) without planned split as suggested by the RTOG, reasons for dis- 
continuation and the outcome of the patients with adherence to continuous treatment.

\section{Patients and Methods}

Between 1988 and 200684 consecutive HIV-negative patients presenting with histologically proven carcinoma of the anal canal were treated with curative EBRT $\pm \mathrm{CT}$ at the Zurich University Hospital, Switzerland and the Centre Hospitalier Universitaire de Montreal, Canada. Ninety-nine percent of the patients had squamous cell carcinoma of the anal canal (SCCAC). Clinical characteristics, pattern of care and outcome were analyzed retrospectively by reviewing medical records and interviews of patients after internal board approval.

Pre-treatment staging according to the American Joint Committee on Cancer and the Union International Contre le Cancer (UICC) included digital examination, endoluminal ultrasound or rectoscopy, chest $\mathrm{x}$-rays and either an abdominal ultrasound or CT scanning. Posttreatment evaluation included digital palpation at each visit and regular anal ultrasounds. Anoscopy with posttreatment biopsies and CT or MR scan were performed when a suspicious lesion was identified. The common terminology criteria for adverse events v3.0 was used for scoring acute and late treatment toxicity. Sphincter function was assessed by digital palpation.

3-D conformal RT (6-, 10-, or 18-MV) was applied via a 4-field plan, a dorso-lateral 3-field plan (usually excluding groins) or an AP/PA 2-field plan with electron fields to the groins to the whole pelvis to a dose of $45 \mathrm{~Gy} / 1.8 \mathrm{~Gy}$ per fraction (Zurich) or via AP/PA opposed fields to a dose of $24 \mathrm{~Gy} / 2$ Gy per fraction (Montreal) using prone or supine position. All patients received an external beam radiotherapy (EBRT) photon boost to the macroscopic tumor region which was delivered via a 2-, 3- or 4-field plan to achieve a total dose of 59.4 Gy (Zurich) or 52 Gy (Montreal). A split of 12 days was intended after whole pelvis irradiation in Montreal whereas no split was intended in Zurich. In Zurich patients developing grade III/IV toxicities (CTC v3.0) treatment was interrupted until side effects resolved. Patients who received a brachytherapy boost in Zurich were not included in the analysis [12]. In Zurich, an EBRT boost was applied to patients who objected an interstitial boost or whose tumor size did not qualify for brachytherapy after $45 \mathrm{~Gy}$ EBRT. In Zurich, patients received groin irradiation only if clinically positive (63\%) whereas in Montreal, all but one patient $(98 \%)$ with negative inguinal lymph nodes received prophylactic EBRT to the bilateral groins at a median dose of 24 Gy (range 20-30 Gy). No bolus was used in either institution. All patients, except 1 patient who died during treatment (Zurich), completed curative RT.
Chemotherapy was applied to patients with more advanced stage disease (larger T2, T3/4, N+) (Zurich) or all patients (Montreal). Chemotherapy consisted of fluorouracil (5-FU) and mitomycin-C (MMC) or occasionally cisplatin. 5-FU was applied continuously during 5 days at $750 \mathrm{mg} / \mathrm{m}^{2}$ or 4 days at $1000 \mathrm{mg} / \mathrm{m}^{2}$ in week 1 and 4 or 5 (Zurich) or over 5 days at $1000 \mathrm{mg} / \mathrm{m}^{2}$ in the first week of each RT series (Montreal). MMC was given as a bolus twice $\left(10 \mathrm{mg} / \mathrm{m}^{2}\right)$ during week 1 and 4 or 5 or once $(15$ $\left.\mathrm{mg} / \mathrm{m}^{2}\right)$ during week 1 (Zurich) or twice $\left(10 \mathrm{mg} / \mathrm{m}^{2}\right)$ in the first week of each RT series (Montreal). Cisplatin was given IV, during 1 hour infusion, in week 1 and 4 or 5 at a dose of $40 \mathrm{mg} / \mathrm{m}^{2} / 1 \mathrm{x}$ (Zurich).

\section{Statistics}

Mean values are indicated with standard deviation. Differences between groups on continuous and categorical variables were tested using the Mann-Whitney test and Fisher's exact test, respectively. Survival was calculated from the beginning of RT to the day of death or the date of last follow-up and time-to-recurrence was calculated from the beginning of RT to the day of recurrence or the date of last follow-up. Survival curves for the two groups were plotted according to the Kaplan-Meier method. Differences in survival across the groups were tested using the Log rank (Mantel-Cox) test. Confidence intervals (CI) were calculated using the formula "95\% CI = M \pm (SE*1.96)". Log rank test was used to analyze the effect of categorical data on risk of recurrence. Linear regression was used to describe the relationship between local control and RT dose of data from the literature.

\section{Results}

\section{Patients and treatment characteristics}

Thirty-two patients with carcinoma of the anal canal were treated in Zurich and 52 patients in Montreal. The 2 cohorts from Zurich and Montreal had similar patient characteristics (Table 1). Patients treated in Zurich were marginally older than patients from Montreal $(61 \pm 13 \mathrm{y}$ vs. $56 \pm 12$ y) $(P=0.07)$ and had more nodal positive disease $(P=0.01)$ (Table 1$)$. RT dose was significantly higher $(P<0.001)$ and mean split duration significantly shorter $(P<0.001)$ in patients from Zurich, though mean overall RT duration time was similar (RT duration includes split). In Zurich, 14 patients (44\%) had no treatment interruption whereas the other 18 patients $(56 \%)$ required a split of any duration. MMC-based chemotherapy was applied more frequently in Montreal $(98 \%$ vs. $78 \%)(P<0.01)$.

\section{Treatment response and survival}

Curative (chemo-) RT resulted in complete response in 94\% of patients at Zurich and Montreal. After a mean follow-up of $40 \pm 27$ months, there was no difference in overall survival $(\mathrm{OS} ; P=0.2$ ) (Figure 1a) or cancer-spe- 
Table 1: Patient characteristics.

\begin{tabular}{|c|c|c|c|}
\hline patient characteristics & $\begin{array}{l}\text { Zurich } \\
(n=32)\end{array}$ & $\begin{array}{c}\text { Montreal } \\
(n=52)\end{array}$ & $P$ \\
\hline \multicolumn{4}{|l|}{ Host factors } \\
\hline Age (years) & $61 \pm 13$ & $56 \pm 12$ & 0.07 \\
\hline gender (\% female) & 69 & 62 & \\
\hline \multicolumn{4}{|c|}{$\begin{array}{l}\text { Anatomical extent tumor size } \\
\text { (\%) }\end{array}$} \\
\hline $\mathrm{T} 1$ & 13 & 15 & \\
\hline $\mathrm{T} 2$ & 28 & 38 & \\
\hline T3 & 38 & 21 & \\
\hline T4 & 22 & 23 & \\
\hline LN involvement (\%) & & & 0.08 \\
\hline No & 43 & 71 & 0.01 \\
\hline $\mathrm{N} 1$ & 17 & 8 & \\
\hline N2 & 23 & 10 & \\
\hline N3 & 17 & 12 & \\
\hline \multicolumn{4}{|l|}{ Treatment-related factors } \\
\hline RT (Gy) & $59.4 \pm 1$ & $52.1 \pm 2$ & $<0.001$ \\
\hline RT duration (days) & $52 \pm 8$ & $50 \pm 8$ & \\
\hline Split duration (days) & $6 \pm 8$ & $14 \pm 7$ & $<0.001$ \\
\hline Inguinal RT (\%) & 56 & 98 & $<0.001$ \\
\hline Chemotherapy (\%) & 81 & 100 & $<0.01$ \\
\hline MMC (\%) & 78 & 98 & $<0.01$ \\
\hline
\end{tabular}

Patient characteristics of patients treated with external beam radiotherapy at Zurich $(n=32)$ and Montreal $(n=52) . M M C=M i t o m y c i n-C, L N$

$=$ lymph node, $\mathrm{RT}=$ radiotherapy.

cific survival (CSS; $P=0.2$ ). The 5 -year OS and CSS in patients from Zurich versus Montreal were 57\% (95\% CI $=37-77 \%)$ versus $67 \%(95 \% \mathrm{CI}=48-86 \%)$ and $74 \%(95 \%$ $\mathrm{CI}=57-91 \%)$ versus $80 \%(95 \% \mathrm{CI}=62-98 \%)$, respectively. At 5 years, there was also no difference in local control ( $78 \%$ vs. $82 \%$ at 5 y) (Figure 1 b) or regional relapse (3\% vs. $11 \%)$ or distant relapse (17\% vs. $8 \%$ ) between patients treated in Zurich or Montreal. Sphincter-preservation at 5 years was achieved in $74 \%$ of patients at Zurich and $79 \%$ of patients at Montreal. Split duration of patients with or without local relapse was $15 \pm 7 \mathrm{~d}$ vs. $14 \pm 7 \mathrm{~d}$ (Montreal, NS) and $11 \pm 11 \mathrm{~d}$ vs. $5 \pm 7 \mathrm{~d}$ (Zurich; $\mathrm{P}<0.001$ ) (Figure $2)$. Overall recurrence probability was associated with advanced T-stage $(P=0.06)$ and $\mathrm{N}$-stage $(P=0.09)$ and increased bowel toxicity $(P=0.05)$ in both cohorts.

In patients from Zurich high-dose (chemo-) radiation of 59.4 Gy was feasible in 14 patients without interruption (44\%) and in 4 patients with a split of less than 7 calendar days resulting in $63 \%$ with a split of less than 7 calendar days. Reasons for treatment interruption were bowel toxicity $(\mathrm{n}=4)(P=0.1)$, dermatitis $(\mathrm{n}=4)(P=$ $0.7)$, hematological toxicity $(n=2)$, fistula $(n=2)$, heart failure $(n=1)$ or vaginal herpes $(n=1)$. Univariate analysis of patient characteristics (BMI, nicotine or ethanol) revealed low body mass index (BMI) being predictive for bowel toxicity $(\mathrm{P}=0.004)$ and radiation treatment interruption of any duration $(P=0.002)$. Similar results have been suggested by a previous report [13].

Patients with prolonged treatment interruption $(\geq 7$ calendar days) showed impaired CSS (51\% vs. 89\%; P = $0.03)$ compared with patients with minor interruption (< $7 \mathrm{~d}$ ) (Figure 3a). Overall survival (47\% vs. $61 \%$; $P=0.18$ ), LC (61\% vs. $90 \%$; $P=0.11$ ) (Figure $3 \mathrm{~b})$ and sphincter preservation (61 vs. $83 \% ; P=0.5)$ did not differ significantly between patients with prolonged $(\geq 7 \mathrm{~d})$ and minor $(<7$ d) treatment interruptions.

\section{Treatment toxicity}

Acute grade $3 / 4$ toxicity was significantly lower in patients from Zurich (44\% vs. $81 \%$; $P=0.0002$ ). Seventy- 

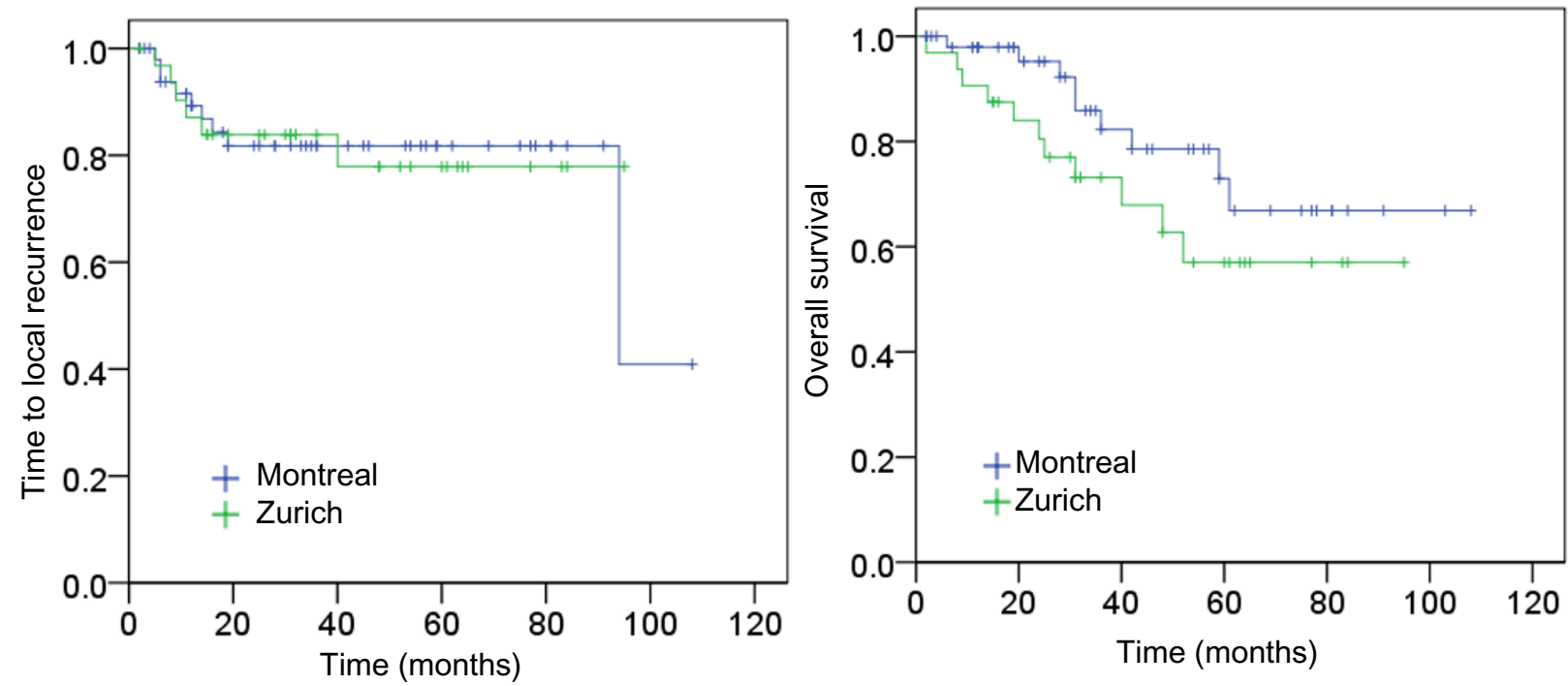

Figure 1 Cumulative survival of the whole cohort. Cumulative survival of patients treated at Zurich ( $n=32$, green line) or Montreal ( $n=52$, blue line). 1a: Time-to-local recurrence. Log rank $P=0.99 \mathbf{1 b}$ : Overall survival. Log rank $P=0.2$.

nine percent of patients treated in Montreal experienced dermatitis grade $3 / 4$ compared with $28 \%$ of patients in Zurich $(P<0.0001)$. The rate of diarrhea grade $3 / 4$ was similar in the Canadian and Swiss cohorts (4\% vs. $13 \%)$ as well as chemotherapy-induced hematological toxicity grade $3 / 4$ (15\% vs. $4 \%$ ). One patient from Zurich died due to hematological toxicity. Bowel toxicity correlated with prolonged RT $(P=0.03)$ in univariate analyses.

Chronic toxicity data were available for $66 \%$ of patients from Zurich. Thirty-three percent of patients experienced chronic side effects equal to or greater than grade

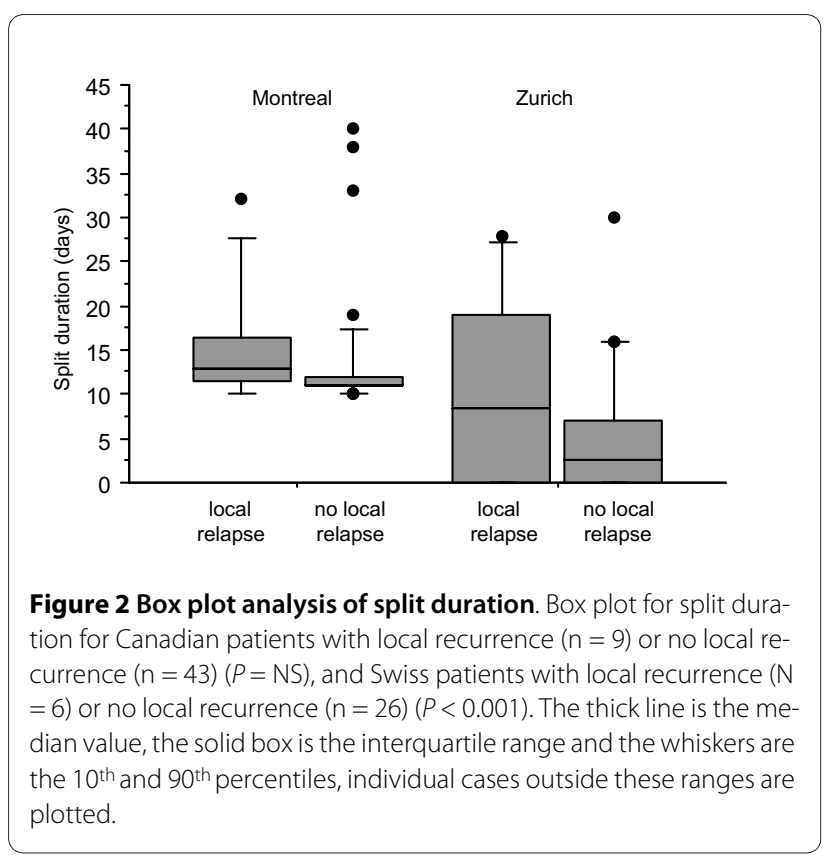

2: proctitis $(40 \%)$, incontinence $(29 \%)$, impaired sphincter tonus $(32 \%)$ or skin ulceration $(5 \%)$.

\section{Review of the literature}

Of 22 studies identified with primary 3D-CRT and concurrent MMC for treatment of anal cancer (4 prospective randomized, 6 prospective non-randomized, 12 retrospective), data on local control were extracted from 18 studies and were used for regression analysis (Table 2, 3). One study was lacking local control data, 2 studies included split and non-split regimens and for 1 study the updated data were used. Linear regression curves of studies with or without mandatory split demonstrated an increase of local control with higher RT doses (Figure 4). The linear regression curve for local control of studies without mandatory split showed a $10 \%$ improved local control through all RT doses compared with studies with mandatory split.

\section{Discussion}

In this retrospective cohort study of 2 institutions comparing modern CRT with or without mandatory split, we found similar overall survival, cancer-specific survival and local control irrespective of split-course regimen. However, different patient characteristics and techniques between the institutions on various levels, and the reluctant use of chemotherapy or prophylactic inguinal RT in many patients in Zurich might have biased treatment outcome. Other limitations of this study are its retrospective character making assessment of toxicity and of cause of death difficult resulting in a relatively low cancer-specific survival. Additionally, patient number was limited 

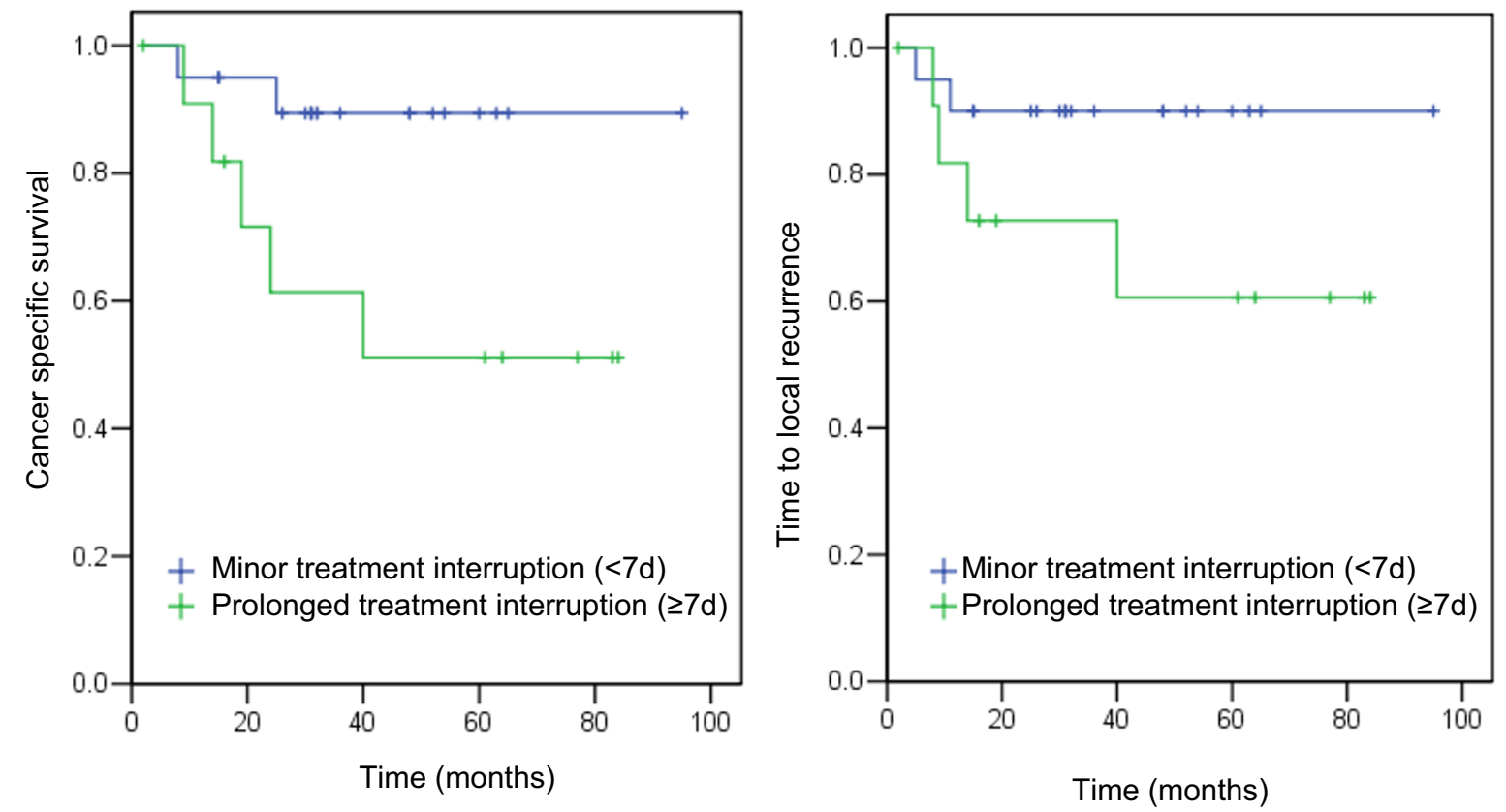

Figure 3 Cumulative survival of patients from Zurich. Cumulative survival of patients treated at Zurich with minor treatment interruption ( $<7$ days) ( $n=14$, blue line) or with prolonged treatment interruption ( $\geq 7$ days) $(n=18$, green line). 3a: Cancer-specific survival. Log rank $P=0.06$ 3b: Time-tolocal recurrence. $\log$ rank $P=0.16$.

and there was a possible treatment bias at Zurich where patients were subjected to either brachytherapy boost or EBRT boost. Adherence to continuous high-dose CRT was feasible in only $44 \%$ of patients from Zurich due to severe toxicity such as enteritis, skin or haematological toxicity or fistulae. Bowel toxicity was associated with prolonged RT duration. Skin toxicity was noticed significantly more frequently in patients treated at Montreal. While outcome in terms of tumor control and survival was comparable between patients without or with unplanned interruption, patients with prolonged unplanned treatment interruption ( $\geq 7 \mathrm{~d}$ ) in the Zurich group seemed to have worse outcome, particularly cancer-specific survival.

Treatment time and RT-dose, together with chemotherapy, are known prognostic factors in SCCAC [25,7,14-18]. Review of the literature revealed 11 studies that evaluated EBRT without prolonged interruption using 3D-CRT and MMC. Two of these studies used RT doses below 50 Gy. Five year local control rates ranged from $79 \%-90 \%[5,8-11,19,20]$. In accordance with the literature, our study demonstrated local control and sphincter preservation rates of $90 \%$ and $83 \%$, respectively, at $5 \mathrm{y}$ after continuous (chemo-) radiation with 59.4 Gy (Zurich). Similar results (87\%) have also been reported by the most recent RTOG study by Ajani et al. using 55-59 Gy/30-32 fractions over intended 5.5 - 6.5 weeks with concurrent MMC [1]. While some studies which compared RT with or without split were unable to find a difference between groups, others showed favorable results or a significant improvement in local control for patients without prolonged unplanned interruption $[8,10,11]$. In accordance with our observations, Weber et al. reported that patients with long unplanned treatment interruption had a significantly worse outcome than patients with short interruption [15]. As shown in Figure 4, cohorts with no major treatment interruption were more likely to have a better local control than cohorts with the same total RT dose but using split-course or interrupted regimens (resulting in a lower biological RT dose). However, some studies with mandatory split regimens also demonstrated excellent local control rates $[2,5,7,11,18]$. Nevertheless, a majority of trials demonstrated impaired local control for interrupted regimens. Data from one comparative study on dose has been published in abstract form (ACCORD 03). Although no details have been provided on treatment interruptions, doses exceeding 60 Gy do not seem beneficiary [21].

An important feature in this study was the suboptimal adherence to continuous CRT of $44 \%$ because of needed treatment interruption due to side effects. Similar results have been reported by Meyer et al. (49\% > 8 d) [11]. Konski et al. reported minor deviation from protocol in $20 \%$ of patients [8]. Reasons for treatment interruption in our 
Table 2: Review of the literature: prospective trials.

\begin{tabular}{|c|c|c|c|c|c|c|c|c|c|c|c|c|c|c|c|}
\hline study & $n$ & Stage & total & $\begin{array}{c}\text { RT dose } \\
\text { (Gy) } \\
\text { pelvic }\end{array}$ & inguinal & Split & CT & OS (\%) & LC (\%) & CFS (\%) & $\begin{array}{l}\text { toxicity } \\
\text { overall }\end{array}$ & skin & diarrhea & BM & $\begin{array}{c}\text { adherence } \\
(\%)\end{array}$ \\
\hline \multicolumn{16}{|l|}{ prospective, randomized } \\
\hline Ajani (2008) & 324 & $\mathrm{~T} 2-4$ & $55-59$ & 45 & 45 & cont & $\mathrm{MMC}, 5-\mathrm{FU}$ & $75(5 y)$ & $87(5 y)^{1}$ & $90(5 \mathrm{y})$ & 87 & 48 & 23 & 61 & \\
\hline RTOG 98-11 & 320 & $\mathrm{~T} 2-4$ & $55-59$ & 45 & 45 & cont & Cispl., 5-FU & $70(5 y)$ & $81(5 y)^{1}$ & $81(5 \mathrm{y})$ & 83 & 41 & 24 & 42 & \\
\hline Flam (1996) & 146 & T1-4N0-3 & $45-50.4$ & 30,6 & $30.6-45$ & split (4 w) & $\mathrm{MMC}, 5-\mathrm{FU}$ & $74(4 \mathrm{y})$ & $84(4 \mathrm{y})$ & $71(4 \mathrm{y})$ & $26^{2}$ & $7^{3}$ & & 18 & \\
\hline RTOG 87-04/ECOG 1289 & & & $\left(59.4^{*}\right)$ & & $\left(54^{*}\right)$ & & & & & & & & & & \\
\hline UKCCR (1997) & 283 & $>\mathrm{T} 1 \mathrm{NO}$ & 604 & 45 & e (45) & split (6 w) & $\mathrm{MMC}, 5-\mathrm{FU}$ & $65(3 y)$ & $61(3 y)$ & & 27 & 17 & 5 & 4 & \\
\hline Bartelink (1997) & 52 & T3-4N0-3 & $60-65$ & 45 & e (60-65) & split (6 w) & $\mathrm{MMC}, 5-\mathrm{FU}$ & $65(5 y)$ & $69 *(5 y)$ & $71(5 \mathrm{y})$ & & 56 & 19 & & \\
\hline EORTC & & $\mathrm{T} 1-2 \mathrm{~N} 1-3$ & & & & & & & & & & & & & \\
\hline \multicolumn{16}{|l|}{$\begin{array}{l}\text { prospective, } \\
\text { non-randomized }\end{array}$} \\
\hline $\begin{array}{l}\text { John (1996), Konsky } \\
\text { (2008) }\end{array}$ & 20 & T1-4N0-3 & 59,6 & $30.6-45^{5}$ & $30.6-45$ & cont & $\mathrm{MMC}, 5-\mathrm{FU}$ & $85(5 \mathrm{y})$ & $90(5 y)$ & $75(5 \mathrm{y})$ & & & & & 80 \\
\hline RTOG 92-08 & 46 & T1-4N0-3 & 59,6 & $30.6-45^{5}$ & $30.6-45$ & split (2 w) & $\mathrm{MMC}, 5-\mathrm{FU}$ & $67(5 y)$ & $73(5 \mathrm{y})$ & $58(5 y)$ & 63 & 32 & 9 & $40^{*}$ & 87 \\
\hline Cummings (1991) & 192 & T1-4N0-3 & $50^{6}$ & 50 & 50 & cont & $\mathrm{MMC}, 5-\mathrm{FU}$ & 75 & 88 & & 75 & & & & \\
\hline \multirow[t]{2}{*}{ PMH } & & T1-4N0-3 & $50^{6}$ & 50 & 50 & split & $\mathrm{MMC}, 5-\mathrm{FU}$ & 65 & 93 & & 50 & & & & \\
\hline & & T1-4N0-3 & 48 & 48 & 48 & split & $\mathrm{MMC}, 5-\mathrm{FU}$ & 65 & 85 & & 36 & & & & \\
\hline Bosset (2003) & 43 & $\mathrm{~T} 2-4 \mathrm{~N} 0-3$ & 59,4 & 36 & e (36) & split (2 w) & $\mathrm{MMC}, 5-\mathrm{FU}$ & $81(3 \mathrm{y})$ & $88(3 y)$ & $81(3 y)$ & & 28 & 12 & 2 & 93 \\
\hline EORTC & & $(>4 \mathrm{~cm})$ & & & & & & & & & & & & & \\
\hline Vuong (2003) & 30 & $\mathrm{~T} 2-4 \mathrm{~N} 0-3$ & 54 & $27-30$ & 27 & cont & MMC, 5-FU & $64(4 \mathrm{y})$ & $91(4 \mathrm{y})$ & & & 20 & 3 & 13 & 100 \\
\hline
\end{tabular}


Table 2: Review of the literature: prospective trials. (Continued)

McGill

Schneider (1992)

$46 \quad$ T0-4N0-3 $50(56-68)^{7}$

50

50

cont

MMC, 5-FU $\quad 84(5 \mathrm{y}) \quad 83(5 \mathrm{y}) \quad 80(5 \mathrm{y})$

35

24

28-35

\section{Erlangen}

Sischy (1989)

$79 \quad \mathrm{~T} 1-4 \mathrm{~N} 0-3$

40,8

40,8

40,8

cont $\quad M M C, 5-F U \quad 73(3 y) \quad 71(3 y)^{8}$

19

1

3

51

$\mathrm{EBRT}=$ external beam radiotherapy, $\mathrm{RT}=$ radiotherapy, $\mathrm{CT}=$ chemotherapy, $\mathrm{T}=$ tumor stage, $\mathrm{N}=$ nodal stage, $\mathrm{w}=$ week, $\mathrm{mo}=$ months, $\mathrm{y}=\mathrm{years}, \mathrm{OS}=$ overall survival, $\mathrm{LC}=\mathrm{local}$ control, $\mathrm{CFS}=$ colostomy-free survival, cont $=$ continuous, e = elective, $1=$ first event, $2=$ grade $4 / 5,3=$ non-hematological, $4=$ alternatively, surgery after $45 \mathrm{~Gy}, 5=$ field reduction after $30.6 \mathrm{~Gy}$ from $L 4 / 5$ to lower sacro-iliac joint, $6=2.5$ Gy per fraction, $7=28 \%$ had an EBRT or brachytherapy boost of 6-18 Gy, $8=$ locoregional. References: Ajani [1], Flam [2], UKCCR [3], Bartelink [4], John [6], Konsky [8], Cummings [5], Bosset [7], Vuong [9], Schneider [20], Sischy [30] 
Table 3: Review of the literature: retrospective trials.

\begin{tabular}{|c|c|c|c|c|c|c|c|c|c|c|c|c|c|c|c|}
\hline study & $\mathbf{n}$ & Stage & total & $\begin{array}{l}\text { RT dose (Gy) } \\
\text { pelvic }\end{array}$ & inguinal & Split & CT & OS (\%) & LC (\%) & CFS (\%) & $\begin{array}{l}\text { toxicity } \\
\text { overall }\end{array}$ & skin & diarrhea & BM & $\begin{array}{c}\text { adheren } \\
\text { ce (\%) }\end{array}$ \\
\hline Vuong (2007) & 62 & $\mathrm{~T} 2-4 \mathrm{~N} 0-3$ & 54 & $27-30$ & $27-30$ & cont & $\mathrm{MMC}^{1}, 5-\mathrm{FU}$ & 81 & 85 & & 37 & 19 & 5 & 13 & 100 \\
\hline McGill & 60 & $\mathrm{~T} 2-4 \mathrm{~N} 0-3$ & 45-58.9 & & & split & $\mathrm{MMC}^{1}, 5-\mathrm{FU}$ & 54 & 61 & & 70 & 43 & 11 & 17 & \\
\hline Meyer (2006) & 35 & $\mathrm{~T} 1-4 \mathrm{~N} 0-3$ & 55,8 & 45 & e (45) & cont $(\leq 1 \mathrm{w})$ & $\mathrm{MMC}, 5-\mathrm{FU}$ & 71 & 85 & 85 & & 29 & 3 & & 50 \\
\hline Hannover & 32 & $\mathrm{~T} 1-4 \mathrm{~N} 0-3$ & 55,8 & 45 & e (45) & split (>1 w) & $\mathrm{MMC}, 5-\mathrm{FU}$ & 63 & 81 & 87 & & 27 & 12 & & \\
\hline Graf (2003) & 38 & T1-4N0-3 & 45 & $30(45)^{2}$ & $30-45$ & cont & $\mathrm{MMC}, 5-\mathrm{FU}$ & & 79 & & & & & & 52 \\
\hline Berlin & 65 & $\mathrm{~T} 1-4 \mathrm{~N} 0-3$ & 45 & $30(45)^{2}$ & $30-46$ & split (1 w) & $\mathrm{MMC}, 5-\mathrm{FU}$ & & 58 & & & & & & \\
\hline Tanum $(1991,1993)$ & 117 & $\mathrm{~T} 1-4 \mathrm{~N} 0-3$ & $50\left(-54^{*}\right)$ & 50 & & cont & $\mathrm{MMC}, 5-\mathrm{FU}$ & 72 & $75-93$ & & & 34 & 9 & 1 & \\
\hline \multicolumn{16}{|l|}{ Oslo } \\
\hline Ferrigno (2005) & 43 & $\mathrm{~T} 1-4 \mathrm{~N} 0-3$ & 55 & 45 & e (55) & cont & $\mathrm{MMC}, 5-\mathrm{FU}$ & $68(5 y)$ & $79(5 y)$ & $52(5 y)$ & & 74 & 44 & 21 & $72^{3}$ \\
\hline \multicolumn{16}{|l|}{ Sao Paolo } \\
\hline Widder (2008) & 108 & T1-4N0-3 & 60 & 30 & $30^{5}$ & split (2-3 w) & $\mathrm{MMC}, 5-\mathrm{FU}$ & 57 & 86 & 51 & & & & & \\
\hline Vienna & 21 & & & & & or cont ${ }^{4}$ & & & & & & & & & \\
\hline Doci (1992) & 56 & $\mathrm{~T} 1-3 \mathrm{~N} 0-3$ & $54-60$ & 36 & 36 & split (2 w) & $\mathrm{MMC}, 5-\mathrm{FU}$ & $81(8 \mathrm{y})$ & $53-74^{*}$ & & & 5 & 4 & 7 & \\
\hline \multicolumn{16}{|l|}{ Milan } \\
\hline Ceresoli (1998) & 35 & $\mathrm{~T} 2-4 \mathrm{~N} 0-3$ & 56 & 45 & e (56) & split (2 w) & MMC, 5-FU & $71(5 \mathrm{y})$ & & $70(3 y)$ & & $75^{*}$ & & $14^{* *}$ & \\
\hline \multicolumn{16}{|l|}{ Milan } \\
\hline Weber (2001) & 45 & $\mathrm{~T} 1-4 \mathrm{~N} 0-3$ & $60^{11}$ & 40 & 40 & split (<38 d) & $\mathrm{MMC}, 5-\mathrm{FU}$ & & $85^{10}$ & & & & & & \\
\hline Geneva & 45 & $\mathrm{~T} 1-4 \mathrm{~N} 0-3$ & $60^{11}$ & 40 & 40 & split (>37 d) & $\mathrm{MMC}, 5-\mathrm{FU}$ & & $62^{10}$ & & & & & & \\
\hline $\begin{array}{l}\text { Constantinou } \\
\text { (1997) }\end{array}$ & 50 & T1-4N0-3 & 54 & $30-36$ & $30-36(45)^{6}$ & split & MMC, 5-FU & $66(5 y)$ & $70(5 \mathrm{y})$ & & & & & & \\
\hline
\end{tabular}


Table 3: Review of the literature: retrospective trials. (Continued)

\section{MGH}

Mai (2008)

90

T1-4N0-3

$50-54$

$30.6(45-50.4)^{9}$

30-36

cont or split ${ }^{8} \quad M M C, 5-F U \quad 86(5 y)^{7} \quad 79(5 y)$

Mannheim

$87 \quad \mathrm{~T} 1-4 \mathrm{~N} 0-3 \quad 55.8-66.4$

50,4

50,4

cont or split $\quad M M C, 5-F U \quad 75(5 y)$

ca. 90

$87(5 \mathrm{y})$

34

35

(2005)

Erlangen

EBRT $=$ external beam radiotherapy, $\mathrm{RT}=$ radiotherapy, $\mathrm{CT}=$ chemotherapy, $\mathrm{T}=$ tumor stage, $\mathrm{N}=$ nodal stage, $\mathrm{w}=$ week, $\mathrm{mo}=\mathrm{months}, \mathrm{y}=\mathrm{years}, \mathrm{OS}=$ overall survival, $\mathrm{LC}=\mathrm{local}$ control, $\mathrm{CFS}=$

colostomy-free survival, cont = continuous, e = elective, $1=\mathrm{MMC}$ or cisplatin, $2=\mathrm{T} 3 / 4$ tumors were treated with $30 \mathrm{~Gy}$ to L4/5, T1-4 45 Gy to lower iliosacral joints, $3=28 \%$ split with $15 \mathrm{~d}$ median $4=16 \%$ continuous, $5=45$ Gy if no staging with CT scan, $6=45$ Gy to medial nodes, $7=$ disease-free survival, $8=75$ pts continuous, 9 pts according to Cummings regimen (48-50 Gy, $4 \mathrm{w}$ split), 6 pts according to RTOG (59.4 Gy, $2 \mathrm{w}$ split), $9=$ field reduction from L4/5 to lower iliosacral joint after $30.6 \mathrm{~Gy}, 10=$ locoregional, $11=$ brachytherapy boost in some patients. References: Vuong [10], Meyer [11], Graf [16], Tanum [26], Widder [18], Doci [23], Ceresoli [31], Weber [15], Ferrigno [19], Mai [24], Grabenbauer [32], Constantinou [17] 

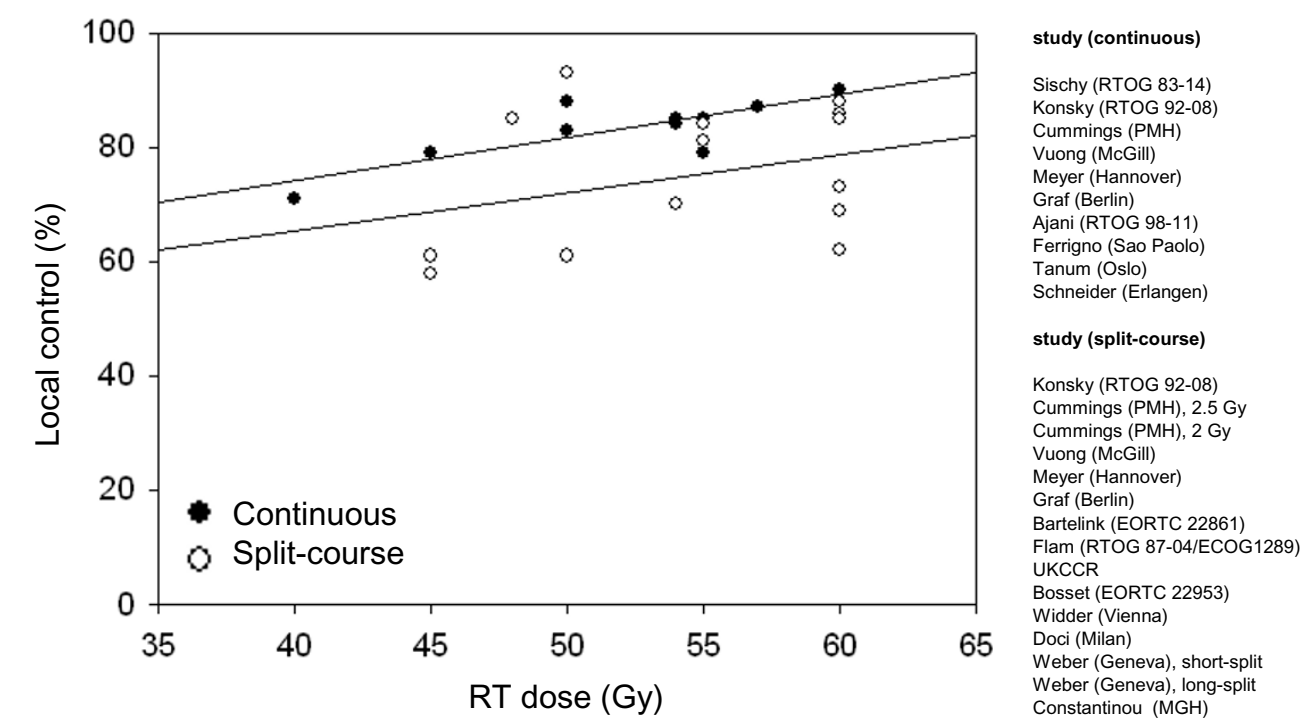

$\begin{array}{cc}\text { RT dose } & \text { LC } \\ 40 & 71 \\ 60 & 90 \\ 50 & 88 \\ 54 & 85 \\ 55 & 85 \\ 45 & 79 \\ 57 & 87 \\ 55 & 79 \\ 54 & 84 \\ 50 & 83 \\ & \\ \text { RT dose } & \text { LC } \\ & \\ 60 & 73 \\ 50 & 93 \\ 48 & 85 \\ 50 & 61 \\ 55 & 81 \\ 45 & 58 \\ 60 & 69 \\ 55 & 84 \\ 45 & 61 \\ 60 & 88 \\ 60 & 86 \\ 54 & 70 \\ 60 & 85 \\ 60 & 62 \\ 54 & 70\end{array}$

Figure 4 Review of studies of local control. Local control rates of studies with or without mandatory split. Linear regression curves (black dots = continuous RT, white dots = split-course RT). RT = radiotherapy, LC = local control.

study were predominantly gastrointestinal toxicity (30\%), followed by dermatitis, fistula, heart failure or vaginal herpes. Additionally, a severe dermatitis rate of $80 \%$ also hampered adherence to planned short split-course RT in patients treated at Montreal. It is unclear whether this high rate of documented skin toxicity was caused by field size (inclusion of the groins) or due to subject interpretation. On the other hand, another study by Vuong et al. demonstrated an adherence rate to continuous high-dose RT of even $100 \%$ (Table 4) [10]. In contrast to our study and the one by Meyer et al., they applied only 27-30 Gy instead of 45 Gy to the whole pelvis, resulting in lower bowel and hematological toxicity. Interestingly, the same group reported recently that using IMRT instead of conventional 3D-CRT resulted in increased hematological side effects due to bone marrow dose and treatment interruption of 1-3 weeks in $24 \%$ of patients [22]. The current RTOG 0529 phase II trial is evaluating adverse events from dose-painted IMRT + 5-FU/MMC compared to the RT+ 5-FU/MMC arm from RTOG 9811.

Elective groin irradiation is controversial. While in North America, prophylactic inguinal irradiation is a routine practice and the RTOG protocols recommend 30.6 Gy in 17 fractions to this area, in Europe, no elective inguinal irradiation is widely applied [7]. The optimal RT dose for prophylactic iliac lymph node irradiation is also unclear. If RT is given together with $\mathrm{CT}$, particularly MMC, 30 - 36 Gy instead of 45 Gy have been used in many trials $[2,8,10,16-18,23,24]$. Pelvic relapse has not been consistently reported but seems to be rather low
$[10,25]$. Similarly low inguinal failure rates have been reported after CRT including prophylactic groin irradiation by Das et al. $(4 \%)$ or others $[25,26]$. However, inguinal failure was also reported to be uncommon $(10 \%)$ without elective inguinal RT [7,27]. Staging with FDGPET and sentinel lymph node biopsy (SLNB) are still investigational but might be helpful in the near future $[28,29]$.

\section{Conclusions}

In this retrospective analysis of two cohorts treated to two different institutional guidelines, mainly differing in the standard use of a mandatory split, efficacy of chemoradiation seemed comparable. However, cause-specific outcome may be impaired by unplanned prolonged interruption. Continuous RT may predispose for enhanced gastrointestinal toxicity. Limiting the total dose to organs at risk and field size optimization is likely to improve adherence to treatment and avoid unplanned RT interruptions. Data of the literature point towards improved local control when adherence to continuous or short mandatory split-course CRT with dose escalation is achieved. RT dose escalation to the primary tumor, using IMRT or arc techniques, in combination with IGRT, merit being investigated, in parallel to other treatment modalities such as combination of MMC with cisplatin, novel agents, induction chemotherapy or consolidative chemotherapy.

Competing interests

The authors declare that they have no competing interests. 
Table 4: Review of the literature: trials using IMRT.

\begin{tabular}{|c|c|c|c|c|c|c|c|c|c|c|c|c|c|c|c|c|}
\hline study & $n$ & Stage & Technique & total & $\begin{array}{c}\text { RT dose } \\
\text { (Gy) } \\
\text { pelvic }\end{array}$ & inguinal & Split & CT & OS (\%) & LC (\%) & CFS (\%) & $\begin{array}{l}\text { toxicity } \\
\text { overall }\end{array}$ & skin & diarrhea & BM & $\begin{array}{c}\text { adheren } \\
\text { ce (\%) }\end{array}$ \\
\hline $\begin{array}{l}\text { Vuong (ASCO } \\
\text { 2008) }\end{array}$ & 26 & & IMRT & $54-59.4$ & 30 & 30 & cont & MMC, 5-FU & & $71(1 \mathrm{y})$ & & & 23 & 4 & 42 & 76 \\
\hline McGill & 40 & & $3 \mathrm{~d}-\mathrm{CRT}$ & $54-59.4$ & 30 & 30 & cont & MMC, 5-FU & & $85(1 \mathrm{y})$ & & & 19 & 3 & 18 & 93 \\
\hline Salama (2007) & $53^{2}$ & $\mathrm{~T} 1-4 \mathrm{~N} 0-3$ & IMRT & 51,5 & 45 & 45 & cont & $\mathrm{MMC}, 5-\mathrm{FU}$ & $93(18 \mathrm{mo})$ & 84 (18 mo) & $84(18 \mathrm{mo})$ & & 38 & 15 & & $58^{1}$ \\
\hline \multicolumn{17}{|l|}{ Chicago } \\
\hline Milano (2005) & 17 & T2-4NO-3 & IMRT & $54-59.4$ & 45 & 45 & cont & $\mathrm{MMC}, 5-\mathrm{FU}$ & $91(2 y)$ & & $82(2 y)$ & & 0 & 0 & 53 & 100 \\
\hline Chicago & & & & & & & & & & & & & & & & \\
\hline
\end{tabular}

IMRT = intensity-modulated radiotherapy, EBRT = external beam radiotherapy, $\mathrm{RT}=$ radiotherapy, $\mathrm{CT}=$ chemotherapy, $\mathrm{T}=$ tumor stage, $\mathrm{N}=$ nodal stage, $\mathrm{w}=$ week, $\mathrm{mo}=\mathrm{months}, \mathrm{y}=\mathrm{years}, \mathrm{OS}=$ overall survival, LC = local control, CFS = colostomy-free survival, cont = continuous, e = elective, $1=$ median 4 d interruption, $2=15 \%$ HIV-positive. References: Vuong [22], Salama [33], Milano [34] 


\section{Authors' contributions}

CO carried out conception and design, collection and assembly of data, data analysis, manuscript writing, SP carried out collection and assembly of data, manuscript writing, data analysis and interpretation, DD carried out data analysis and interpretation, manuscript writing, JPB manuscript writing, UML carried out data analysis and interpretation, manuscript writing, IFJ carried out conception and design, financial support, data analysis and interpretation, manuscript writing. All authors read and approved the final manuscript.

\section{Acknowledgements}

Supported in part by the Radium Fund of the University of Zurich, Zurich, Switzerland and unrestricted grants from Merck Sharp Dome, Inc. and Abbott Laboratories, Inc. (to IFC).

\section{Author Details}

'Department of Radiation Oncology, Zurich University Hospital, Zurich, Switzerland, 2Department of Radiation Oncology, Fleurimont Hospital, Centre Hospitalier Universitaire de Sherbrooke (CHUS), Sherbrooke, Canada, ${ }^{3}$ Department of Radiation Oncology, Hôpital de Notre-Dame, Center Hospitalier Universitaire de Montreal (CHUM), Montreal, Canada, ${ }^{4}$ Radiation Oncology, Klinikum Dessau, Dessau, Germany and ${ }^{5}$ Center for Clinical Research, Zurich University Hospital, Zurich, Switzerland

Received: 13 January 2010 Accepted: 13 May 2010

Published: 13 May 2010

\section{References}

1. Ajani JA, Winter KA, Gunderson LL, et al:: Fluorouracil, mitomycin, and radiotherapy vs fluorouracil, cisplatin, and radiotherapy for carcinoma of the anal canal: a randomized controlled trial. Jama 2008 , 299:1914-1921.

2. Flam M, John M, Pajak TF, et al: Role of mitomycin in combination with fluorouracil and radiotherapy, and of salvage chemoradiation in the definitive nonsurgical treatment of epidermoid carcinoma of the ana canal: results of a phase III randomized intergroup study. J Clin Oncol 1996, 14:2527-2539.

3. Epidermoidanal cancer: results from the UKCCCR randomised trial of radiotherapy alone versus radiotherapy, 5 -fluorouracil, and mitomycin. UKCCCR Anal Cancer Trial Working Party. UK Co-ordinating Committee on Cancer Research. Lancet 1996, 348:1049-1054.

4. Bartelink H, Roelofsen F, Eschwege F, et al:: Concomitant radiotherapy and chemotherapy is superior to radiotherapy alone in the treatment of locally advanced anal cancer: results of a phase III randomized trial of the European Organization for Research and Treatment of Cancer Radiotherapy and Gastrointestinal Cooperative Groups. J Clin Oncol 1997, 15:2040-2049.

5. Cummings BJ, Keane TJ, O'Sullivan B, et al: Epidermoid anal cancer: treatment by radiation alone or by radiation and 5 -fluorouracil with and without mitomycin C. Int J Radiat Oncol Biol Phys 1991, 21:1115-1125

6. John M, Pajak T, Flam M, et al:: Dose Escalation in Chemoradiation for Anal Cancer: Preliminary Results of RTOG 92-08. Cancer J Sci Am 1996, 2:205

7. Bosset JF, Roelofsen F, Morgan DA, et al: Shortened irradiation scheme, continuous infusion of 5-fluorouracil and fractionation of mitomycin $C$ in locally advanced anal carcinomas. Results of a phase II study of the European Organization for Research and Treatment of Cancer. Radiotherapy and Gastrointestinal Cooperative Groups. Eur J Cancer 2003, 39:45-51.

8. Konski A, Garcia M Jr, John M, et al:: Evaluation of planned treatment breaks during radiation therapy for anal cancer: update of RTOG 92-08. Int J Radiat Oncol Biol Phys 2008, 72:114-118.

9. Vuong T, Devic S, Belliveau P, et al: Contribution of conformal therapy in the treatment of anal canal carcinoma with combined chemotherapy and radiotherapy: results of a phase II study. Int J Radiat Oncol Biol Phys 2003, 56:823-831.

10. Vuong T, Kopek N, Ducruet T, et al: Conformal therapy improves the therapeutic index of patients with anal canal cancer treated with combined chemotherapy and external beam radiotherapy. Int J Radiat Oncol Biol Phys 2007, 67:1394-1400.
11. Meyer A, Meier Zu Eissen J, Karstens JH, Bremer M: Chemoradiotherapy in patients with anal cancer: impact of length of unplanned treatment interruption on outcome. Acta Oncol 2006, 45:728-735.

12. Oehler-Janne C, Seifert B, Lutolf UM, et al:: Clinical outcome after treatment with a brachytherapy boost versus external beam boost for anal carcinoma. Brachytherapy 2007, 6:218-226.

13. Huang EY, Wang CJ, Chen HC, et al:: Multivariate analysis of pulmonary fibrosis after electron beam irradiation for postmastectomy chest wall and regional lymphatics: evidence for non-dosimetric factors. Radiother Oncol 2000, 57:91-96.

14. Allal $A S$, Mermillod $B$, Roth $A D$, et al:: The impact of treatment factors on local control in T2-T3 anal carcinomas treated by radiotherapy with or without chemotherapy. Cancer 1997, 79:2329-2335.

15. Weber DC, Kurtz JM, Allal AS: The impact of gap duration on local control in anal canal carcinoma treated by split-course radiotherapy and concomitant chemotherapy. Int J Radiat Oncol Biol Phys 2001, 50:675-680

16. Graf $R$, Wust $P$, Hildebrandt $B$, et al:: Impact of overall treatment time on local control of anal cancer treated with radiochemotherapy. Oncology 2003, 65:14-22

17. Constantinou EC, Daly W, Fung CY, et al:: Time-dose considerations in the treatment of anal cancer. Int J Radiat Oncol Biol Phys 1997, 39:651-657.

18. Widder J, Kastenberger R, Fercher E, et al:: Radiation dose associated with local control in advanced anal cancer: retrospective analysis of 129 patients. Radiother Oncol 2008, 87:367-375.

19. Ferrigno R, Nakamura RA, Dos Santos Novaes PE, et al. Radiochemotherapy in the conservative treatment of anal canal carcinoma: retrospective analysis of results and radiation dose effectiveness. Int J Radiat Oncol Biol Phys 2005, 61:1136-1142.

20. Schneider IH, Grabenbauer GG, Reck T, et al:: Combined radiation and chemotherapy for epidermoid carcinoma of the anal canal. Int J Colorectal Dis 1992, 7:192-196.

21. Conroy T, Ducreux M, Lemanski C, et al.: Treatment intensification by induction chemotherapy (ICT) and radiation dose escalation in locally advanced squamous cell anal canal carcinoma (LAAC): Definitive analysis of the intergroup ACCORD 03 trial. J Clin Oncol 2009:27. abstr 4033

22. Vuong $\mathrm{T}$, Faria $\mathrm{S}$, Ducruet $\mathrm{T}$, et al.: Changes in treatment toxicity pattern using the combined treatment of patients with anal canal cancer and early local recurrence results associated with the introduction of new radiation technologies: 3D conformal therapy and intensity modulated radiation therapy. ASCO Meeting, Edition; 2008. Abstract \#4608

23. Doci R, Zucali R, Bombelli L, et al:: Combined chemoradiation therapy for anal cancer. A report of 56 cases. Ann Surg 1992, 215:150-156.

24. Mai SK, Welzel G, Hermann B, et al.: Long-term outcome after combined radiochemotherapy for anal cancer - retrospective analysis of efficacy, prognostic factors, and toxicity. Onkologie 2008, 31:251-257.

25. Das $P, B$ Batia $S$, Eng $C$, et al.: Predictors and patterns of recurrence after definitive chemoradiation for anal cancer. Int J Radiat Oncol Biol Phys 2007, 68:794-800

26. Tanum G, Tveit K, Karlsen KO, Hauer-Jensen M: Chemotherapy and radiation therapy for anal carcinoma. Survival and late morbidity. Cancer 1991, 67:2462-2466.

27. Gerard JP, Chapet O, Samiei F, et al:: Management of inguinal lymph node metastases in patients with carcinoma of the anal canal: experience in a series of 270 patients treated in Lyon and review of the literature. Cancer 2001, 92:77-84.

28. Nguyen BT, Joon DL, Khoo V, et al:: Assessing the impact of FDG-PET in the management of anal cancer. Radiother Oncol 2008, 87:376-382.

29. Gretschel S, Warnick P, Bembenek A, et al.: Lymphatic mapping and sentinel lymph node biopsy in epidermoid carcinoma of the anal canal. Eur J Surg Oncol 2008, 34:890-894.

30. Sischy B, Doggett RL, Krall JM, et al:: Definitive irradiation and chemotherapy for radiosensitization in management of anal carcinoma: interim report on Radiation Therapy Oncology Group study no. 8314. J Natl Cancer Inst 1989, 81:850-856.

31. Ceresoli GL, Ferreri AJ, Cordio S, Villa E: Role of dose intensity in conservative treatment of anal canal carcinoma. Report of 35 cases. Oncology 1998, 55:525-532.

32. Grabenbauer GG, Kessler H, Matzel KE, et al.: Tumor site predicts outcome after radiochemotherapy in squamous-cell carcinoma of the anal 
region: long-term results of 101 patients. Dis Colon Rectum 2005, 48:1742-1751.

33. Salama JK, Mell LK, Schomas DA, et al:: Concurrent chemotherapy and intensity-modulated radiation therapy for anal canal cancer patients: a multicenter experience. J Clin Oncol 2007, 25:4581-4586.

34. Milano MT, Jani AB, Farrey KJ, et al:: Intensity-modulated radiation therapy (IMRT) in the treatment of anal cancer: toxicity and clinical outcome. Int J Radiat Oncol Biol Phys 2005, 63:354-361.

doi: 10.1186/1748-717X-5-36

Cite this article as: Oehler et al., Chemo-radiation with or without mandatory split in anal carcinoma: experiences of two institutions and review of the literature Radiation Oncology 2010, 5:36

Submit your next manuscript to BioMed Central and take full advantage of:

- Convenient online submission

- Thorough peer review

- No space constraints or color figure charges

- Immediate publication on acceptance

- Inclusion in PubMed, CAS, Scopus and Google Scholar

- Research which is freely available for redistribution

Submit your manuscript at www.biomedcentral.com/submit
() BioMed Central 